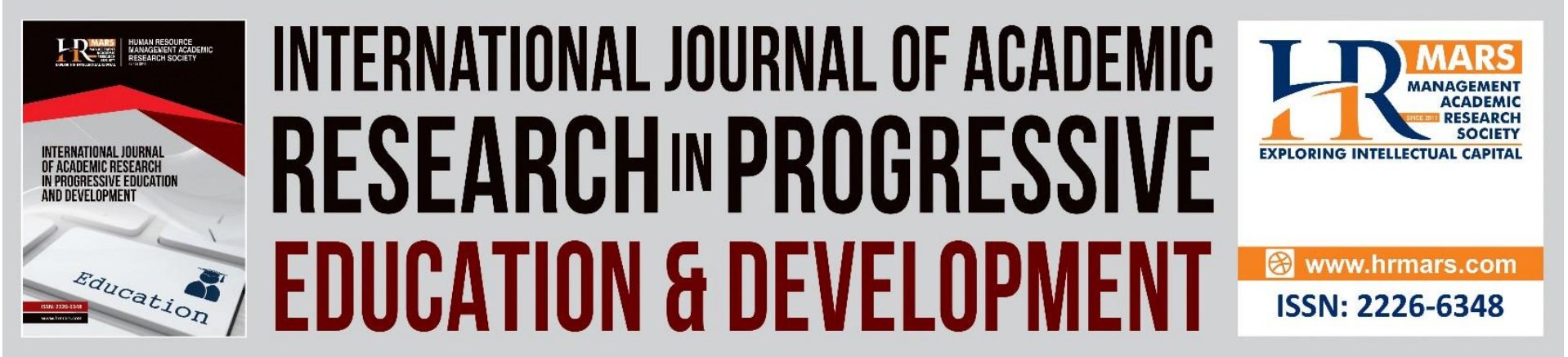

\title{
WebEx Breakout Sessions: Enhancing Student Engagement during Remote Learning
}

Muhammad Noor Abdul Aziz, Marcia Jane Ganasan, Nurahimah Mohd Yusoff

To Link this Article: http://dx.doi.org/10.6007/IJARPED/v10-i3/11283

DOI:10.6007/IJARPED/v10-i3/11283

Received: 08 July 2021, Revised: 12 August 2021, Accepted: 14 September 2021

Published Online: 29 September 2021

In-Text Citation: (Aziz et al., 2021)

To Cite this Article: Aziz, M. N. A., Ganasan, M. J., \& Yusoff, N. M. (2021). WebEx Breakout Sessions: Enhancing Student Engagement during Remote Learning. International Journal of Academic Research in Progressive Education and Development, 10(3), 1002-1014.

Copyright: @ 2021 The Author(s)

Published by Human Resource Management Academic Research Society (www.hrmars.com)

This article is published under the Creative Commons Attribution (CC BY 4.0) license. Anyone may reproduce, distribute, translate and create derivative works of this article (for both commercial and non-commercial purposes), subject to full attribution to the original publication and authors. The full terms of this license may be seen at: http://creativecommons.org/licences/by/4.0/legalcode

Vol. 10(3) 2021, Pg. 1002 - 1014

http://hrmars.com/index.php/pages/detail/IJARPED

JOURNAL HOMEPAGE

Full Terms \& Conditions of access and use can be found at http://hrmars.com/index.php/pages/detail/publication-ethics 


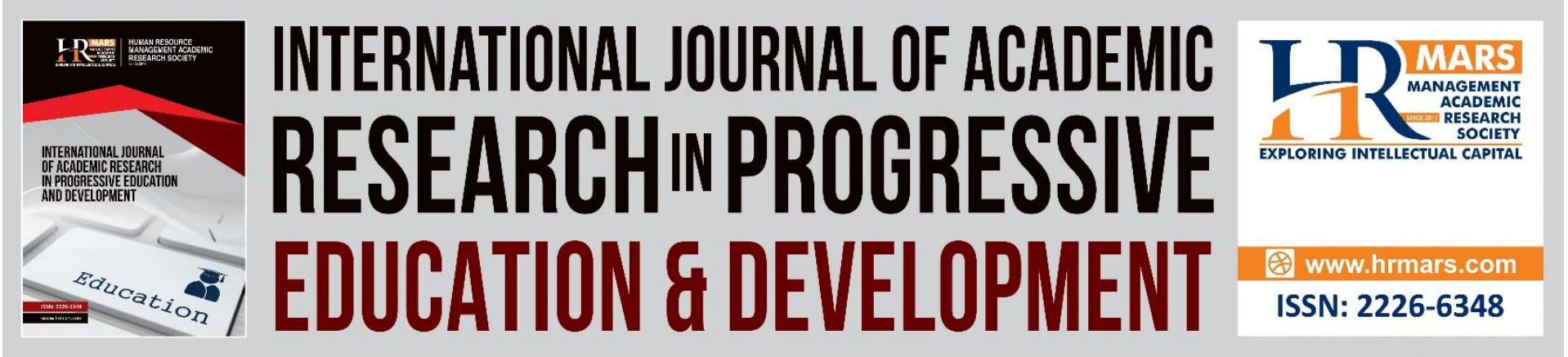

\title{
WebEx Breakout Sessions: Enhancing Student Engagement during Remote Learning
}

\author{
Muhammad Noor Abdul Aziz¹, Marcia Jane Ganasan², \\ Nurahimah Mohd Yusoff ${ }^{3}$ \\ ${ }^{1,3}$ School of Education, Universiti Utara Malaysia, 06010 Sintok, Kedah, ${ }^{2}$ Academy of \\ Language Studies, UiTM Arau, Perlis.
}

\begin{abstract}
Remote learning is the new norm in education. For the past year, it is globally accepted that it has become the routine for all educators and learners, specifically in higher education, to adopt remote learning as their forced choice of teaching and learning mode. However, it invites glitches in lesson delivery and classroom activities to adjust to ensure meaningful teaching and learning occur during online classes. One of the most significant problems is student engagement. Since synchronous learning is part of the lecture method used in higher education, WebEx offers breakout groups that enable learners to mix and mingle online to share thoughts and present ideas. This current study seeks to explore learning activities and strategies adopted via WebEx to increase learner engagement. Through a series of participant observations and student reflection entries from Padlet, the researchers provide some insights from course participants. 4 themes emerged from the data - Engaging lessons, Interesting activities, Positive vibes, and Improving communication. The findings from this study can be used in preparing a module on using WebEx effectively with students in higher education.
\end{abstract}

Keywords: Remote Learning, WebEx, Engagement, Synchronous

\section{Introduction}

The world came to a halt when the Coronavirus disease became a pandemic and hit the globe. Every aspect of our lives was severely affected. Education systems globally went into an immediate online mode with various methods being introduced and implemented. Amir et al (2020) revealed from their study that one of the preferred modes of learning by students in higher education is remote learning. During emergency remote schooling, support for optimal pacing may be especially crucial. This pace is crucial for learners as some may become fatigued (Carter et al., 2020). Dhawan (2020) addressed those academic institutions may now take advantage of remote learning by having their instructors teach and students learn online since both academics and students have been comfortable and have never explored new learning methods. 
DEVELOPMENT

Vol. 10, No. 3, 2021, E-ISSN: 2226-6348 @ 2021 HRMARS

Siemens' connectivism idea (Siemens, 2005) serves as the theoretical foundation for this study. Connectivism asserts that learning is not restricted to individuals but can also be accomplished through group or peer-to-peer interactions that use the internet to discover and create new learning possibilities. Connectivism alleviates time constraints by allowing students to work at their own speed, either individually or collectively. Teachers, especially remotely, guide the students, while the network facilitates their learning. Siemens also shared the underlying principles in connectivism as in Figure 1, which are imperative to be understood and implemented as much as teaching and learning online is concerned.

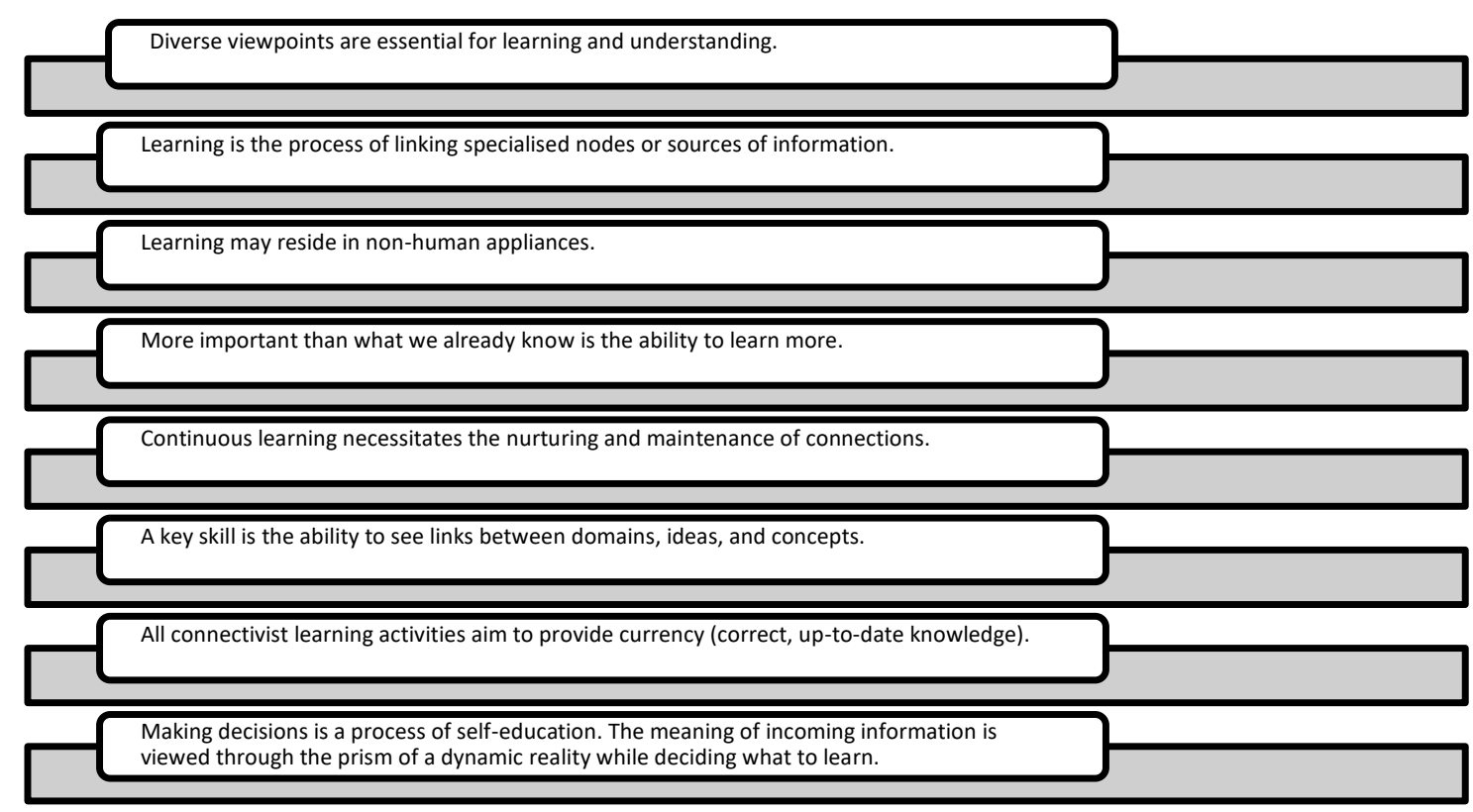

Figure 1. Principles of connectivism

The impact of remote learning has consciously forced educators to upgrade their technical knowledge and prepare interactive lessons to make lesson delivery meaningful. However, even though instructors meet the students during the classes, there are still issues of student engagement in online classes (Gillett-Swan, 2017; Dhawan, 2020). In addition, most students were stressed with the long lectures (Rosalina et al., 2020; Amir et al., 2020), and they were dissatisfied (Fatoni et al., 2020). Apart from that, many students hoped for more interactive activities (Khlaif et al., 2021).

Past studies have discovered that student engagement is essential during online learning because it is one of the determinants of student success (Hope, 2021). Educators also felt that student engagement was pivotal in making learning sessions fruitful and motivating (Deepika, 2020). Therefore, if educators do not seriously consider student engagement, the entire process of adapting to online learning would invite more hiccups than it already does.

Zoom, Google Meet and WebEx are among synchronous real-time platforms chosen by educators to meet their students online. WebEx is a video conferencing platform used by many instructors from universities in Malaysia. One of the exciting features of WebEx is the breakout sessions. The breakout sessions are designed to provide meaningful and engaging discussions for students. Instructors can attempt to integrate various digital tools while having 
students in groups during synchronous learning. As such, this study seeks to explore learning activities and strategies adopted via WebEx breakout sessions to increase learner engagement during remote learning. It is timely that research is carried out on how learning is sustained during the pandemic, whether the learning channels used to cater for students' learning styles, and mitigation strategies as contingency plans for continued learning during and after the pandemic (Jimola \& Ofodu, 2021).

\section{Materials and Methods Materials}

In this study, the researchers analysed 62 synchronous lessons which lasted for two hours weekly. It was the class of two undergraduate courses in the field of English education at two universities in northern Malaysia. The classes consisted of 70 trainee teachers and 4 course instructors. The instructors conducted the lectures for approximately 25 minutes for all the lessons, and the remaining hours would be WebEx breakout session activities.

During the breakout sessions, the instructors would divide the students into groups of five which altered during every class. They intended to make the students mingle with their friends from various backgrounds, ethnicities, gender, and religions. They also attempted to assess the courses' learning clusters, which dealt with social skills, by having the students in different groups.

Throughout the 14 weeks of remote learning, the students were tasked to embark on an array of activities, namely lyric construction, infographic poster design, debates, discussions, Padlet entries, video review and also projects to engage with community via online platforms.

\section{Methodology}

To garner data for this case study, the researchers adopted a qualitative approach to explore more profound students' experiences (Hammarberg et al., 2016) during WebEx breakout sessions. The researchers were actively involved as participant observers in the online classes whenever possible, or recorded lessons were watched and analysed using an observation checklist adapted from Yang and Cornelius (2004). In addition, during the classes, the researchers joined the different breakout sessions and prompted the students with some probing questions to get their responses.

Besides, the students uploaded their reflection entries weekly on the class Padlet. This tool was enthusiastically used by both the instructor and the students. They would also share additional materials on the course to assist every member in the class.

For this study, the researchers also semi-structurally interviewed 25 students who were selected purposively after their reflections were read and analysed. The interview protocols from Richardson et al. (2020) and Yang and Cornelius (2004) were adopted in aiding this study. The researchers found out that the students shared insights that were pertinent to the research area being studied. All the data collected were shared with the instructors and another expert in online learning for validation purposes and to avoid interpreters' bias. Data collected from the observation, reflection entries and interviews were also triangulated 
to establish trustworthiness besides using Atlas ti.version 9 to ease and document their analysis systematically. The researchers knew that the data reached its point of inductive thematic saturation (Saunders et al., 2018) when they saw the codes were repetitive. Rigorous coding and categorising were carried out by highlighting the repetitive phrases and words from the data to see the emerging patterns (Braun \& Clarke, 2019). Initially, nine themes were generated, but after the expert raters' agreement and comments, they were collapsed into 4 meaningful themes: Engaging lessons, Interesting activities, Positive vibes, and Improving communication. The Cronbach's Alpha reliability value for the themes after the raters assessed them was 0.89 . The presence of a high total Alpha indicated that the scale was reliable (Taber, 2018).

\section{Results and Discussion}

Theme 1: Engaging lessons

The students elaborated using their Padlets that the lessons carried out with WebEx breakout sessions were engaging and stimulating and the breakout sharing sessions influenced their thought processes. Students also reported that they were feeling excited and engaged during their breakout sessions as they discovered the features and application of the tools. The instructor employed video clips, podcasts and voice to help students to engage in their lessons as well as giving them the time to make observations as part of their active learning process.

"I am very happy my lecturer give us to meet during breakout. I did not see my friend so long, at least can see them in the video. Yeah we do have chit chats in Whatsapp, but in breakout sessions, we discuss and I feel like I am in class" (Reflection Participant 13)

"The students can joke among themselves and share different emojis to support their friends' ideas during the breakout session. They even switched on their video which they did not do during the lecture" (Observation 4)

"My friends always say good, good when I share during the WebEx breakout sessions. I am more comfortable in the breakout than in the class (lecture) because it is a small group." (Interview P24)

“I wasn't feeling shy to express my opinion because we were all given the chance to speak up and share our thoughts" (Reflection Participant 8)

"Many of my friends and myself included are enjoying the features on WebEx, it is convenient and we can still have our sharing without any interruptions" (Reflection Participant 15) 
The breakout sessions made the delivery of lessons effective and engaging using the features through the use of mic, chatbox and sharing. The participants discussed in smaller groups and the instructor was able to facilitate each group catering to their questions and answers. This platform provided space for strategic attention and concerns raised by the groups. From an observational standpoint,the students' participants listened attentively to their peers during the sharing session and utilized the 'Raise Hand' feature when they joined again in the main room. This allows students to engage continuously and participate meaningfully creating two-way communication online.

Theme 2: Interesting activities

Another recurring theme that was established from the breakout session was activities. Students reported that there were exciting activities that the students were able to engage in during the breakout rooms. They felt that the activities helped them grasp the lessons comprehensively when supplemented with the activities. In other words, students are aware that breakout sessions have become part of their distance learning. The instructor set the breakout rooms for four students for every session each to share their thoughts about a passage that was just read, a review question, making an inference through the use of media tools.

"A youtube video link was given to each group. They had to watch the short clip on how moral values were integrated in lessons in Thailand. The students shared in the chat box that it made them cry."(Observation 1)

"I liked it when Dr. gave us the task to make an infographic poster via canva. We made it together during the class. I learnt from my friend how to convert it to powerpoint." (Interview P7)

"The best activity for this semester was the debate. We had a good time preparing our points to fight the next group during the lecture. I love it!" (Reflection Participant 10)

"Dr. asked us to create a lyric of a song to convey a message on saving the earth. We all discuss in breakout and one of my friends from Sabah actually can sing the song. He created a song and it was so nice." (Interview P21)

"I am very surprised that we could do so much in class during our breakout session. It is something I look forward to in every lesson."

(Participant 37) 
"Online learning can be interesting and we are connected with fun activities done with our lecturer and coursemates" (Reflection Participant 60)

The students expressed their excitement with the activities that they were tasked to do. Activities also include ice breakers, prompts and polls were used as part of the learning instruction which helped form virtual meetings among the community of learners. Most of the activities incorporated various uses of multimedia tools for classroom management. In addition to that, as a token of reward and appreciation, students were awarded marks for their active role and participation in the virtual classroom which bolstered their motivation and engagement. However, for an improved virtual learning experience, students need to have self-directional skills to navigate through WebEX features to participate in the activities.

Theme 3: Positive Vibes

Another theme that stemmed from this study was emotional engagement. The breakout sessions provided students the platform to respond and share their feat in challenging times. As students were in their respective breakout rooms, many were observed openly sharing about their challenges. The common issues and challenges faced by the students are juggling house chores, sickness, poor bandwidth, and confusion when attempting to complete their assignments. Students showed empathy and solidarity through words of encouragement, using emojis, and cracked light jokes to lighten up the environment. Therefore, online social networking platforms even within the confines of the classroom are necessary for students' discussion beyond official online lesson time.

"One student said that he and his whole family were infected with Covid-19 and he was in the quarantine centre. The other members in the breakout sessions offered a prayer for him and motivated him by telling him to stay strong." (Observation 43)

"I am tired at home that I need to do work for family and listen to lecture. I like Dr's class because I can talk to my friend and Dr also always ask if I am ok. I feel good after the class" (Reflection Participant 8)

"After we finish the task, we always chat a while in breakout session. I can ask my friends if I don't know how to do assignment. I think breakout is helpful." (Interview P9)

"I feel lighter when i share my concerns with my friends, it is therapeutic and i am happy that my friends encourage me most times" (Interview P12)

"Listening and hearing out from one another, make me feel that im not alone in this, $i$ have friends who go 
through similar or even worse experiences" (Reflection Participant 35)

Peer engagement and support systems facilitate students' engagement that also lead to the engagement of collaboration and motivation. It was relieving that the students always looked forward to the breakout sessions to share positivity and support each other. Social interaction is a powerful learning experience when combined with collaboration as it encourages the processing of 'social brain' particularly when students are faced with challenges during remote learning. Emotional engagement during classroom discussion takes place when students show empathy and display gestures that indicate understanding and compassion from the listeners.

Theme 4: Improve communication

Apart from learning the subject matter, the students also articulated that their communication skills were being tested during the WebEx breakout sessions, making them want to improve more. When students are able to enact behaviorally and effectively, their communicative abilities improve as students progress in their lessons. This is in part because participants felt more comfortable joining the conversation and this approach decreases feelings of insecurity and shyness amidst a smaller number of participants. Another unique finding that stood out from the data was small sized group meetings favored students from various personalities particularly those with an introverted personality trait. This also points out that, within a breakout session, students have the opportunity of sharing their thoughts in a more natural-feeling state that establishes bonding and group solidarity..

"Dr. said that if we talk in English, he will give bonus marks. But I am shy to talk to Dr. What I do, I talk to my friend in breakout. There we laugh, but we also learn." (Interview P13)

"My communication is better when I talk during breakout. I can share materials when I talk with my friends in breakout. I always tell Dr. to have breakout sessions every week at least 20 minutes." (Reflection Participant 6)

"I share my thoughts freely, I am comfortable with my peers and we do not hold back,since we have known one another better with time, i can flow with my thoughts and speech" (Interview, Participant 7)

"Dr, having a closed room makes me feel more myself as im an introverted person, i can share my opinions" (Interview, Participant 53)

"Speaking more confidently, i realized this breakout room gives us the opportunity to share my perspective along 
with others, hearing from them helps me listen better" (Reflection Participant 53)

The breakout sessions managed to help the students to practice their communication skills, which became an alternative platform during remote learning. From the above thematic analysis, it can be pinpointed that breakout sessions have exhibited a myriad of purposes. It steers students' mood, makes lessons more meaningful, embedding interesting activities as well as improving communication skills with the rest of the group members. Figure 2 shows the codes and their relations to the themes generated from the findings.

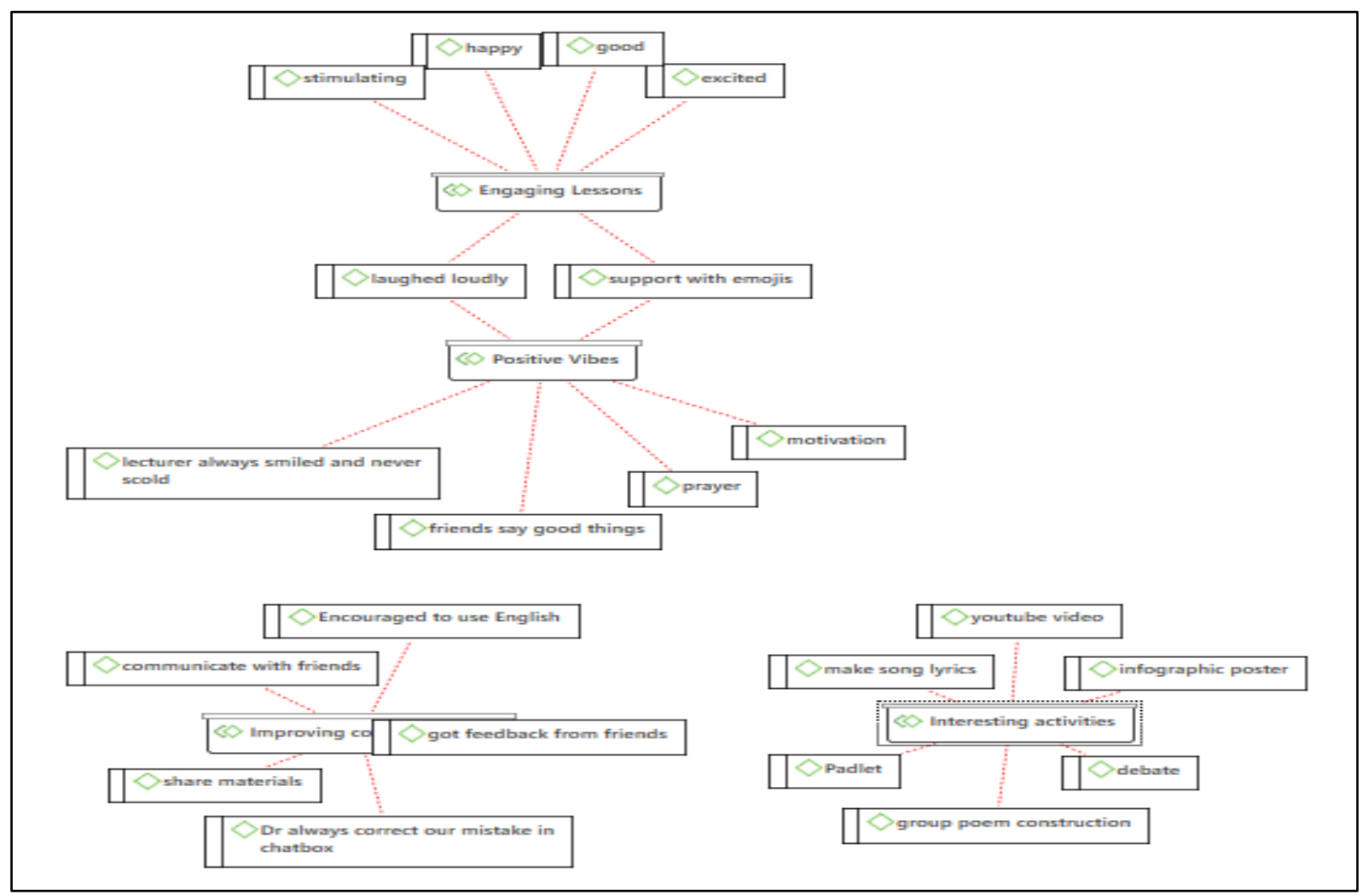

Figure 2. Relationships of the codes and the themes

From the analysis, it is evident that instructors can create engaging lessons using breakout sessions as tools for teaching and learning. According to Lenz et al. (2015), education is a serious matter that should always be carried out enjoyably providing emotional support as part of learning. The two entities of learning and emotions could not be separated as they are closely related to one another. As evidenced in this case study, nearly all students stated that they felt uplifted when they had participated in WebEx activities throughout the lesson which led to increased motivation among students. Although the platform of WebEX may appear plain where more features could be used as part of the platform, the incorporation of breakout session has proved its usefulness when it comes to improving students' affective and behavioral engagement.

This is an important issue that concerns instructors where students are able to work as a team cooperatively. Since peer instruction is the core of this study, Wilson (2019) suggested that group discussion improves students' knowledge significantly because it drives 
them to clarify their ideas, which can be enough to identify loopholes in reasoning. This scenario is palpable with students in this research where they were able to show engagement and enjoyment in their discussion sessions with their peers in the midst of the pandemic Covid-19. The researchers suggest that a useful and meaningful classroom learning could be achieved through the incorporation of breakout sessions. However, instructors are required to facilitate and set the tone through activities and lesson plans that allow students to brainstorm and prepare room for discussion. In addition to that, the tasks assigned to the learners must be interesting and intriguing, non-routined and resemble realistic tasks. After learning, the students should be able to demonstrate their comprehension in a real-world environment. The learners should create a valuable output, which can be yielded from the assessment component in the learning process. In addition to this, Roddy et al. (2017) elucidated that a flexible and responsive approach to all activities is essential in online environments. It is the call the instructors make in ensuring the high engagement of the learners in online learning. Students learn through the use of all senses which include cognitive, visual, hearing, observing affective domains as well. These elements are interrelated and form solid grounding in students' learning purview.

Positive vibes and acts go a long way in engaging learners in learning sessions, especially during a pandemic. Serhan (2020) shared that one of the learners in the class expressed her gratitude to the instructor for his unwavering support and positive spirit, even though there were some primary fears and technical hiccups during online learning. In this study, a student clearly said that the positive vibes from friends, on the other hand, made her quarantine period more bearable since she was confined in her room for fourteen days. It is also claimed by Qin (2020) in her research that positive teachers' emotional support behaviour can help learners improve their learning emotions. The researchers also suggest that from the findings of the study, educators could moderate group discussions that connect students positively from a social aspect such as having a chat scheduled as a topic of the day. With interesting activities coupled with real life everyday talk integrated as part of warm up activity, students' emotions are better prepared and regulated for 'positive vibes'.

Subsequently, the findings of the study also highlighted that the students also believed that their communication skills were elevated while actively immersing themselves in the online activities. Communication is an important aspect of learning and what more with an online, it could be difficult to monitor students communication and interaction, as educators may not be able to 'see' students' gestures and faces in an online setting particularly when students choose to turn off their videos. Such conundrum daunt educators when it comes to ensuring a two way communication with their students. The findings propose that breakout sessions help in attaining an effective communication with the participants as it is effortless, students feel less apprehensive of being judged and they are able to share views and perspectives freely. Therefore, cooperative communication skills can be developed when group discussions are held (Silalahi \& Hutauruk, 2020). It is parallel with the events in this study where the students excitedly mentioned that their spoken English improved and they were able to speak fluently online. 


\section{Conclusion}

From the discussion gathered from the aforementioned, two conclusions are drawn from the findings. Firstly, there are various opportunities available online to engage learners where educators could employ in their lessons through the use of breakout sessions. Educators could also choose new tools available from an online platform in making engaging and interesting lessons. The tools could be integrated in their lesson plans to create and deliver meaningful lessons. Therefore, it is timely that instructors employ technology and tools related to Web 2.0 as part of their teaching. Secondly, learner engagement is a vital component in achieving learning outcomes. It is becoming a great challenge for educators to gauge students' engagement via an online mode. However, it is possible to curate online lessons and teaching where students are able to connect and learn with their coursemates and lecturers virtually through the use of digital tools. From this study, it was found that breakout sessions were handy as students gained confidence and felt comfortable with time. For instance, mini discussions even with a large sized classroom was interactive and was found to be engaging between participants and their instructor. The active and lively environment during the group discussion was attainable through the integration of breakout sessions. Prior to that, an important aspect that should not be disregarded as part of creating a meaningful lesson is to foster social-emotional connections with a mindful inquiry in virtual learning. Educators need to be mindful to design and implement online activities integrating this aspect as part of their teaching plan online. The implications of this study suggest that more interactive activities should be embedded during virtual lectures to enhance students' engagement online. A module on interactive teaching and learning activities should be designed to assist lecturers in choosing what is best for their class. Hence, it is imperative that educators put in the effort to engage learners during remote learning in order for them to gain autonomy in their learning. Future research should also focus on how different types of online platforms could possibly increase student engagement due to the myriad of tools and platforms that are increasing online. Best practices from instructors from various parts of the world could be documented and chaired as a sharing session or as webinars for many struggling educators in tackling teaching and learning difficulties during the pandemic a success.

\section{Corresponding Author}

Muhammad Noor Abdul Aziz

School of Education, UUM, 06010, Sintok, Kedah.

Email: matno@uum.edu.my

\section{References}

Amir, L. R., Tanti, I., Maharani, D. A., Wimardhani, Y. S., Julia, V., Sulijaya, B., \& Puspitawati, R. (2020). Student perspective of classroom and distance learning during COVID-19 pandemic in the undergraduate dental study program Universitas Indonesia. BMC Medical Education, 20(1), 1-8. https://doi.org/10.1186/s12909-020-02312-0

Braun, V., \& Clarke, V. (2019). Successful qualitative research : A practical guide for beginners. SAGE Publications.

Carter, R. A., Rice, M., Yang, S., \& Jackson, H. A. (2020). Self-regulated learning in online learning environments: strategies for remote learning. Information and Learning Science, 121(5-6), 311-319. https://doi.org/10.1108/ILS-04-2020-0114 
Deepika, N. (2020). The impact of online learning during COVID-19: students' and teachers' perspective. The International Journal of Indian Psychology, 8(2), 784-793. https://doi.org/10.25215/0802.094

Dhawan, S. (2020). Online learning: A panacea in the time of COVID-19 crisis. Journal of Educational Technology Systems, 49(1), 5-22. https://doi.org/10.1177/0047239520934018

Gillett-Swan, J. (2017). The Challenges of Online Learning: Supporting and Engaging the Isolated Learner. Journal of Learning Design, 10(1), 20. https://doi.org/10.5204/jld.v9i3.293

Hammarberg, K., Kirkman, M., \& De Lacey, S. (2016). Qualitative research methods: When to use them and how to judge them. Human Reproduction, 31(3), 498-501. https://doi.org/10.1093/humrep/dev334

Hope, J. (2021). Pandemic hampers student engagement, highlights inequities. Enrollment Management Report, 24(12), 9-9. https://doi.org/10.1002/emt.30755

Jimola, F. E., \& Ofodu, G. O. (2021). Sustaining learning during COVID-19 seismic shift: The need to develop flexible pedagogy. Interdisciplinary Journal of Education Research, 3(1), 13-26. https://doi.org/10.51986/ijer-2021.vol3.01.02

Khlaif, Z. N., Salha, S., \& Kouraichi, B. (2021). Emergency remote learning during COVID-19 crisis: Students' engagement. Education and Information Technologies, 0123456789. https://doi.org/10.1007/s10639-021-10566-4

Lenz, B., Wells, J., \& Kingston, S. (2015). Transforming schools using project-based learning, performance assessment, and common core standards. Jossey-Bass Publishers.

Qin, Y. (2020). The research about the role and influence of teacher emotional support in online learning environment. July.

Richardson, J. W., Lingat, J. E. M., Hollis, E., College, R., \& Pritchard, M. (2020). Shifting teaching and learning in online learning spaces: An investigation of a faculty online teaching and learning initiative. Online Learning Journal, 24(1), 67-91. https://doi.org/10.24059/olj.v24i1.1629

Roddy, C., Amiet, D. L., Chung, J., Holt, C., Shaw, L., McKenzie, S., Garivaldis, F., Lodge, J. M., \& Mundy, M. E. (2017). Applying best practice online learning, teaching, and support to intensive online environments: An integrative review. Frontiers in Education, 2(November), 1-10. https://doi.org/10.3389/feduc.2017.00059

Saunders, B., Sim, J., Kingstone, T., Baker, S., Waterfield, J., Bartlam, B., Burroughs, H., \& Jinks, C. (2018). Saturation in qualitative research: exploring its conceptualization and operationalization. Quality and Quantity, 52(4), 1893-1907. https://doi.org/10.1007/s11135-017-0574-8

Serhan, D. (2020). Transitioning from face-to-face to remote learning: Students' attitudes and perceptions of using Zoom during COVID-19 pandemic. International Journal of Technology in Education and Science, 4(4), 335-342. https://doi.org/10.46328/ijtes.v4i4.148

Siemens, G. (2005). Connectivism : A learning theory for the digital age. International Journal of Instructional Technology and Distance Learning, 2(1). http://www.itdl.org/

Silalahi, T. F., \& Hutauruk, A. F. (2020). The application of cooperative learning model during online learning in the pandemic period. Budapest International Research and Critics Institute (BIRCI-Journal): Humanities and Social Sciences, 3(3), 1683-1691. https://doi.org/10.33258/birci.v3i3.1100 
Taber, K. S. (2018). The use of Cronbach's Alpha when developing and reporting research instruments in Science education. Research in Science Education, 48(6), 1273-1296. https://doi.org/10.1007/s11165-016-9602-2

Wilson, G. (2019). Ten quick tips for creating an effective lesson. PLoS Computational Biology, 15(4), 1-12. https://doi.org/10.1371/journal.pcbi.1006915

Yang, Y., \& Cornelius, L. F. (2004). Students' perceptions towards the quality of online education: A qualitative approach. Association for Educational Communications and Technology, 861-877. 